\title{
Association between glucose variation and lower extremity amputation incidence in individuals with type 2 diabetes: a nationwide retrospective cohort study
}

\author{
Chia-Ing Li ${ }^{1,2}$ (D) Hui-Man Cheng ${ }^{3,4} \cdot$ Chiu-Shong Liu ${ }^{1,2,5} \cdot$ Chih-Hsueh Lin ${ }^{1,5} \cdot$ Wen-Yuan Lin ${ }^{1,5} \cdot$ Mu-Cyun Wang ${ }^{1,5}$. \\ Shing-Yu Yang ${ }^{6}$ - Tsai-Chung $\mathrm{Li}^{6,7}$. Cheng-Chieh Lin ${ }^{1,2,5}$
}

Received: 18 June 2019 / Accepted: 23 August 2019/Published online: 4 November 2019

(C) Springer-Verlag GmbH Germany, part of Springer Nature 2019

\begin{abstract}
Aims/hypothesis Elevated glucose level is one of the risk factors for lower extremity amputation (LEA), but whether glycaemic variability confers independent risks of LEA remains to be elucidated. This study aimed to investigate the association between visit-to-visit glycaemic variability and minor and major LEA risks during 8 years of follow-up in type 2 diabetic individuals aged 50 years and older.

Methods This retrospective cohort study included 27,574 ethnic Chinese type 2 diabetic individuals aged $\geq 50$ years from the National Diabetes Care Management Program in Taiwan. Glycaemic variability measures were presented as the CVs of fasting plasma glucose (FPG-CV) and of $\mathrm{HbA}_{1 \mathrm{c}}\left(\mathrm{A}_{1 \mathrm{c}}-\mathrm{CV}\right)$. The effect of glycaemic variability on the incidence of LEA events was analysed using Cox proportional hazards models.

Results After a median follow-up of 8.9 years, 541 incident cases of LEA with a crude incidence density rate of 2.4 per 1000 person-years were observed. After multivariate adjustment, FPG-CV and $\mathrm{A}_{1 \mathrm{c}}-\mathrm{CV}$ were found to be significantly associated with minor LEA, with corresponding HRs of 1.53 (95\% CI 1.15, 2.04) and 1.34 (95\% CI 1.02, 1.77) for the third tertiles of FPG-CV and $\mathrm{A}_{1 \mathrm{c}} \mathrm{CV}$, respectively. In addition, these associations were stronger amongst older adults with longer diabetes duration ( $\geq 3$ years) than amongst those with shorter duration $(<3$ years $)\left(p_{\text {interaction }}<0.01\right)$.

Conclusions/interpretation Our study suggests that visit-to-visit variations in $\mathrm{HbA}_{1 \mathrm{c}}$ and $\mathrm{FPG}$ are important predictors of minor LEA amongst older adults with type 2 diabetes, particularly for those with more than 3 years of diabetes duration.
\end{abstract}

Keywords Glycaemic variability · Lower extremity amputation · Type 2 diabetes

\section{Abbreviations}

$\mathrm{A}_{1 \mathrm{c}}-\mathrm{ARV}$

$\mathrm{A}_{1 \mathrm{c}}-\mathrm{CV}$

Average real variability in $\mathrm{HbA}_{1 \mathrm{c}}$

$\mathrm{CV}$ of $\mathrm{HbA}_{1 \mathrm{c}}$
ARV

$\mathrm{CHF}$

CKD
Average real variability Congestive heart failure Chronic kidney disease

Electronic supplementary material The online version of this article (https://doi.org/10.1007/s00125-019-05012-7) contains peer-reviewed but unedited supplementary material, which is available to authorised users.

Tsai-Chung Li

tcli@mail.cmu.edu.tw

$\triangle$ Cheng-Chieh Lin

cclin@mail.cmuh.org.tw

1 School of Medicine, College of Medicine, China Medical University, 91 Hsueh-Shih Road, Taichung 40402, Taiwan

2 Department of Medical Research, China Medical University Hospital, Taichung, Taiwan
3 School of Chinese Medicine, College of Chinese Medicine, China Medical University, Taichung, Taiwan

4 Department of Integration of Traditional Chinese and Western Medicine, China Medical University Hospital, Taichung, Taiwan

5 Department of Family Medicine, China Medical University Hospital, Taichung, Taiwan

6 Department of Public Health, College of Public Health, China Medical University, 91 Hsueh-Shih Road, Taichung 40402, Taiwan

7 Department of Healthcare Administration, College of Medical and Health Science, Asia University, Taichung, Taiwan 


\section{Research in context}

\section{What is already known about this subject?}

- Evidence from meta-analysis research indicates that raised $\mathrm{HbA}_{1 \mathrm{c}}$ is associated with an increased incidence of lower extremity amputation (LEA)

- Limited evidence is available regarding the relationship between glucose variability and the risk of LEA in individuals with diabetes

\section{What is the key question?}

- What are the effects of visit-to-visit variation in fasting plasma glucose and $\mathrm{HbA}_{1 \mathrm{c}}$ on minor and major LEA risks in individuals with type 2 diabetes?

\section{What are the new findings?}

- $\quad$ The present study indicated that CVs of both fasting plasma glucose (FPG-CV) and $\mathrm{HbA}_{1 c}\left(\mathrm{~A}_{1 \mathrm{c}}-\mathrm{CV}\right)$ exert independent effects on minor LEA risk

- Amongst individuals with more than 3 years of diabetes duration, those with FPG-CV $\geq 34.8 \%$ and $A_{1 c}-C V \geq 16.7 \%$ had increased minor LEA risks of $94 \%$ and $51 \%$, respectively

How might this impact on clinical practice in the foreseeable future?

- Individuals with high glucose variation should be recognised early and monitored closely in order to prevent amputation

$\begin{array}{ll}\text { COPD } & \begin{array}{l}\text { Chronic obstructive pulmonary disease } \\ \text { FPG }\end{array} \\ \text { FPG-ARV } & \begin{array}{l}\text { Fasting plasma glucose } \\ \text { Average real variability in fasting plasma } \\ \text { glucose }\end{array} \\ \text { FPG-CV } & \begin{array}{l}\text { CV of fasting plasma glucose } \\ \text { International Classification of Disease, 9th }\end{array} \\ \text { ICD-9-CM } & \begin{array}{l}\text { Revision, Clinical Modification } \\ \text { Lower extremity amputation }\end{array} \\ \text { NEA } & \begin{array}{l}\text { National Diabetes Care Management Program } \\ \text { NHCMP }\end{array} \\ \text { National Health Insurance Research Database } \\ \text { NHI } & \text { National Health Insurance } \\ \text { PAD } & \text { Peripheral artery disease } \\ \text { PIN } & \text { Personal identification number }\end{array}$

\section{Introduction}

The worldwide prevalence of diabetes has substantially increased and was $8.4 \%$ in individuals aged between 18 and 99 years old in 2017, which corresponds to 451 million individuals globally; this number is expected to rise to 693 million by 2045 [1]. In Taiwan, the prevalence was $9.8 \%$ in 2013 and is projected to rise to $13.1 \%$ in 2035 [1]. This overall increase leads to growth in the number of incident cases of diabetes-related complications, including peripheral neuropathy, peripheral artery disease (PAD) and lower extremity amputation (LEA).

Several risk factors associated with LEA, such as ethnicity, sex, smoking habits, body weight, hypertriacylglycerolaemia, years of diabetes duration, insulin therapy and elevated glucose level, have been identified [2-7]. Amongst them, two glucose-related biomarkers, that is, fasting plasma glucose (FPG) and $\mathrm{HbA}_{1 \mathrm{c}}$, are the primary therapeutic targets of diabetes management to achieve adequate glycaemic control for long periods of time. Individuals with diabetes and high FPG levels are likely to have an amputation $[6,7]$. A meta-analysis reported that every $1 \%$ increase in $\mathrm{HbA}_{1 \mathrm{c}}$ is associated with an increased LEA incidence [8].

$\mathrm{HbA}_{1 \mathrm{c}}$ is the gold standard for blood glucose control monitoring, and it is associated with diabetes complication risk [9, 10]. However, the interpretation is complicated, partly because $\mathrm{HbA}_{1 \mathrm{c}}$ merely reflects the mean blood sugar for the past 3 months; it fails to reflect glycaemic variability and cannot capture the risks associated with extreme glycaemic swings, conferring an additional risk of diabetes-related complications $[11,12]$. In the last decade, glycaemic variability has been an emerging glucose control marker and has been treated as a target for diabetes management. Several systematic reviews have reported a positive relationship between diabetesrelated complications and glycaemic variability, including variability in $\mathrm{HbA}_{1 \mathrm{c}}$ [13] and short-term blood glucose variation (self-monitoring of blood glucose or continuous glucose monitoring without considering $\mathrm{HbA}_{1 \mathrm{c}}$ variability) $[14,15]$ in type 1 and type 2 diabetes mellitus. The association between $\mathrm{HbA}_{1 \mathrm{c}}$ variability and wound healing in foot ulcers has been explored in individuals with diabetes [16], but no study has reported the relationship between glucose variability and risk of LEA in individuals with diabetes. Thus, additional data are needed to characterise the effects of glucose variability on incident LEA. This study examined whether visit-to-visit 
glucose variation, presented as CVs of FPG (FPG-CV) and of $\mathrm{HbA}_{1 \mathrm{c}}\left(\mathrm{A}_{1 \mathrm{c}}-\mathrm{CV}\right)$, has an independent association with minor and major LEA incidences in Chinese individuals with type 2 diabetes who participated in the National Diabetes Care Management Program (NDCMP) in Taiwan.

\section{Methods}

\section{Study population}

The Taiwan Diabetes Cohort Study, a retrospective cohort study, was composed of 50,491 enrolees from the Taiwan NDCMP, who were aged 50 years and over during 20022004 and were diagnosed with diabetes on the basis of the ADA criteria (International Classification of Disease, 9th Revision, Clinical Modification [ICD-9-CM] code 250). This study had two sources of datasets: the NDCMP (2002-2004) and the National Health Insurance Research Database (NHIRD) (1996-2011) (electronic supplementary material [ESM] Fig. 1). The NDCMP dataset provided clinical information for individuals at each visit, such as blood glucose tests for deriving 1 year glucose variation. We used the admission and outpatient claim databases of NHIRD from 1996 to 2003 to exclude individuals who had LEA before entry and to ascertain the LEA events and baseline medications and comorbidities. After excluding those who were ineligible (1392 individuals with type 1 diabetes and 296 individuals with LEA), 48,803 individuals remained. A total of 27,574 individuals remained after further excluding those who could not provide at least 1 year of follow-up blood tests for deriving visit-to-visit variation in FPG and $\mathrm{HbA}_{1 \mathrm{c}}(n=19,561)$, because of joining the NDCMP after 1 January 2014, and those who had missing data on baseline characteristics, diabetes-related variables, comorbidities and laboratory urinary and blood tests $(n=1668)$ (ESM Fig. 2). To evaluate the potential bias arising from the exclusion of those who did not have 1 year follow-up measurements for blood glucose tests, we used standardised effect size to evaluate the baseline differences and found no difference (all standardised effect sizes $<0.1$ ) except for FPG and $\mathrm{HbA}_{1 \mathrm{c}}$ (slightly higher than 0.1 ), indicating that this kind of error might be random, and a low threat to validity (ESM Table 1). This study was approved by the Human Research Committee of China Medical University Hospital. The methods were conducted in accordance with the relevant guidelines and regulations. Informed consent of the study participants was not required because the study was a secondary data analysis using a dataset consisting of de-identified data that were released for research purposes.

\section{Datasets for baseline and follow-up assessments}

The National Health Insurance (NHI) programme, a universal insurance system, was launched in 1995. This national insurance programme had covered approximately $99 \%$ of the entire population (23.74 million people) in Taiwan since 1999 and had contracts with $100 \%$ of hospitals and $92 \%$ of clinics nationwide in 2010. The NHI Bureau randomly audits claims data. To enhance the validity of the claims data, expert reviews were conducted quarterly on every 50-100 inpatient and ambulatory claims in each hospital and clinic. Every false diagnostic report incurred a severe penalty, which was administered by the NHI Bureau. We used datasets for inpatient care by admission and outpatient care for visits during 1996-2011 to exclude individuals who had LEA before entry and to ascertain LEA during the follow-up period. The personal identification number (PIN) of all individuals was scrambled cryptographically for security and privacy purposes by the NHIRD and was used for linkage amongst datasets, including the NDCMP registry and all NHI datasets. Information on demographic data, date and source of diagnosis, outpatient care, inpatient admission and outpatient and inpatient treatments was included in the NHIRD. Disease status was ascertained by the ICD-9-CM. The withdrawal rate of enrolees was very low under the comprehensive coverage of the NHI programme. Thus, bias due to loss to follow-up rate was trivial.

All enrolees underwent assessment upon entry to the NDCMP, which included a series of urinary and blood tests, body measurements and ascertainment of disease status and complication history. A case management nurse administered a standardised, computerised questionnaire to record disease and medication histories and lifestyle behaviours. After a $12 \mathrm{~h}$ overnight fast, blood was drawn in the morning and sent for analysis within $4 \mathrm{~h}$ post collection.

\section{Measurements}

Sociodemographic factors, biomarkers and comorbidities Sociodemographic variables, lifestyle habits and anthropometric measurements were retrieved from the NDCMP database in 2002-2004. The information included age, sex, diabetes duration, smoking status, alcohol consumption status and BMI. Smoking and alcohol consumption statuses were categorised into two: yes and no. Diabetes duration was derived by calculating the number of days between the dates of entry to NDCMP and diabetes onset and then dividing by 365 days. BMI, systolic blood pressure, diastolic blood pressure, serum creatinine, total cholesterol, high-density lipoprotein, low-density lipoprotein, $\mathrm{HbA}_{1 \mathrm{c}}$, FPG and triacylglycerols at the entry date to NDCMP were also retrieved. Measurements of FPG and $\mathrm{HbA}_{1 \mathrm{c}}$ within the 1 year period after entry date for each individual were analysed to calculate $\mathrm{CV}$ and average real variability (ARV) in FPG and $\mathrm{HbA}_{1 \mathrm{c}} \cdot \mathrm{CV}$ 
and ARV were considered because these two measures reflect long-term visit-to-visit glycaemic variation rather than withinday or within-multiple-day glycaemic fluctuation. CV was chosen because it measures the relative variability by weighting the mean. FPG-CV, ARV in FPG (FPG-ARV), $\mathrm{A}_{1 \mathrm{c}}-\mathrm{CV}$ or $\mathrm{ARV}$ in $\mathrm{HbA}_{1 \mathrm{c}}\left(\mathrm{A}_{1 \mathrm{c}}-\mathrm{ARV}\right)$ was calculated only when an individual had two or more FPG or $\mathrm{HbA}_{1 \mathrm{c}}$ measurements in the first year after enrolment. To adjust for the impact of visit number on variation, the $\mathrm{CV}$ value was divided by the square root of the ratio of visit number divided by visit number minus 1 [17]. The ARV values for FPG and $\mathrm{HbA}_{1 \mathrm{c}}$ were calculated by the summation of absolute differences in two consecutive measurements divided by total visits minus 1 [18]. Individuals were classified into subgroups according to tertiles of FPG-CV, $\mathrm{A}_{1 \mathrm{c}}-\mathrm{CV}$, FPG-ARV and $\mathrm{A}_{1 \mathrm{c}}-\mathrm{ARV}$. Serum creatinine was used to derive the eGFR by using the Chronic Kidney Disease Epidemiology Collaboration equation that had been recalibrated for individuals of Chinese ancestry [19].

The exposure periods for comorbidities and hypoglycaemic drugs were defined as the 1 year period preceding entry to the cohort using ambulatory and inpatient claims data. The comorbidities included PAD (ICD-9-CM codes 443.9 and 440.21), hypertension (401-405), hyperlipidaemia (272), coronary artery disease $(410-413,414.01-414.05,414.8$ and 414.9$)$, cancer $(140-149,150-159,160-165,170-175,179-189,190-$ 199, 200, 202, 203, 210-213, 215-229, 235-239, 654.1, $654.10,654.11,654.12,654.13$ and 654.14), atrial fibrillation (427.31), congestive heart failure (CHF) $(428,398.91$ and 402.x1), stroke (430-438), chronic obstructive pulmonary disease (COPD) (490-496), chronic hepatitis (571, 572.2, 572.3, $572.8,573.1,573.2,573.3,573.8$ and 573.9), diabetes-related retinopathy (362.0 and 250.5), hypoglycaemia (2510-2512), peripheral neuropathy (356), foot ulcer (707.1 and 440.23) and alcohol dependence (303 and 305).

Outcome ascertainment By using the unique PIN, we linked the study participants to inpatient claims records (2002-2011) to identify the first episodes of primary or secondary procedure codes for minor amputation, referring to any LEA below the ankle joint (ICD-9-CM codes 84.11-84.12), and/or major amputation, referring to any LEA above the ankle joint (ICD9-CM codes 84.13-84.19) [20]. The study period was between 1 January 2002 and 31 December 2011. The cohort was followed up over 8 years from the index date to 31 December 2011 or until LEA events, death or withdrawal from the insurance programme occurred.

\section{Statistical analysis}

We assessed the normality of variables by visually assessing the histogram curves and conducting the KolmogorovSmirnov test. If the variables were normally distributed, continuous variables were presented as the mean (standard deviation); otherwise, they were presented as the median (interquartile range). Number and percentage were presented for categorical variables. Baseline characteristics were compared between LEA status by the $\chi^{2}$ test or Fisher's exact test for categorical variables and by one-way ANOVA for continuous variables. The relationships of FPG-CV and $\mathrm{A}_{1 \mathrm{c}} \mathrm{C}-\mathrm{CV}$ categories with minor or major LEA risks were assessed by Cox proportional hazards models. HRs and their 95\% CIs were presented by adjusting for age, sex and multiple variables. Three multivariate models were conducted, and the first one adjusted for age at entry (continuous) and sex (male, female). The second model additionally adjusted for lifestyle behaviours and diabetes-related factors of alcohol consumption (yes, no), smoking (yes, no), diabetes duration (continuous), types of hypoglycaemic drugs (no medication, sulfonylurea monotherapy, metformin monotherapy, oral glucose-lowering drug monotherapy other than sulfonylurea or metformin [glucose-lowering-drug-other], sulfonylurea plus metformin combination, sulfonylurea plus glucose-lowering-drug-other combination, metformin plus glucose-lowering-drug-other combination, two glucose-lowering-drug-others, three glucose-lowering drugs, more than three glucose-lowering drugs, insulin monotherapy, insulin plus one glucose-lowering drug, insulin plus two or more glucoselowering drugs), antihypertensive medication (yes, no), obesity (yes, no) and baseline FPG (continuous). The third model further adjusted for comorbidities at baseline, such as CHF (yes, no), coronary artery disease (yes, no), chronic kidney disease (CKD) (eGFR <60 ml min ${ }^{-1} 1.73 \mathrm{~m}^{-2}$ ), cancer (yes, no), hyperlipidaemia (yes, no), PAD (yes, no), atrial fibrillation (yes, no), hypertension (yes, no), stroke (yes, no), COPD (yes, no), chronic hepatitis (yes, no), hypoglycaemia (yes, no), diabetes-related retinopathy (yes, no), foot ulcer (yes, no), peripheral neuropathy (yes, no) and alcohol dependence (yes, no). The linear trend was examined across the FPG-CV and $\mathrm{A}_{1 \mathrm{c}}-\mathrm{CV}$ categories. We also tested the proportionality assumption by entering an interaction term for the quartiles of FPG-CV and $\mathrm{A}_{1 \mathrm{c}}-\mathrm{CV}$ with person-time in the multivariate Cox models. Likelihood ratio tests were applied to explore the interactions of FPG-CV and $\mathrm{A}_{1 \mathrm{c}}-\mathrm{CV}$ with diabetes duration by adding their product terms into the full model for statistical significance. In addition, a dose-response (log-linearity) or non-linear association between each glucose variation variable and LEA outcome was checked by restricted cubic splines in Cox models, and the Wald test was used to test its statistical significance. The multiple imputation method was used to handle missing data in $\mathrm{A}_{1 \mathrm{c}}{ }^{-}$ CV and FPG-CV based on information on baseline variables. SAS version 9.4 (SAS, Cary, NC, USA) was used for all analyses. Two-tailed $p$ values were considered, and statistical significance was considered at $p<0.05$.

\section{Results}

A total of 541 incident LEA cases (310 minor, 195 major and 36 both minor and major LEA cases) were ascertained in our 
cohort during a median 8.9 years of follow-up, resulting in a crude incidence density rate of 2.4 per 1000 person-years. In the subgroups of the first, second and third tertiles, the crude minor LEA incidence density rates per 1000 person-years of FPG-CV were 0.9, 1.5 and 2.3 for minor LEA and 0.7, 1.0 and 1.3 for major LEA; those of $\mathrm{A}_{1 \mathrm{c}}-\mathrm{CV}$ were 1.1, 1.6 and 1.9 for minor LEA and $0.9,1.0$ and 1.2 for major LEA, respectively. The crude incidence density rates for minor and major LEA were 1.3 and 0.9 per 1000 person-years in women and 1.8 and 1.2 per 1000 person-years in men, respectively.
Table 1 shows the baseline characteristics according to the LEA status. Individuals with LEA were more likely to be male and smokers and have high mean age, diabetes duration, and prevalence of $\mathrm{CHF}$, hypertension, stroke, COPD, hypoglycaemia and diabetes-related retinopathy. Figure 1 shows the Kaplan-Meier cumulative incidence curves for LEA within subgroups of 1 year $\mathrm{A}_{1 \mathrm{c}}-\mathrm{CV}$ and FPG-CV. Individuals with $\mathrm{A}_{1 \mathrm{c}}-\mathrm{CV} \geq 16.7 \%$ and $\mathrm{FPG}-$ $\mathrm{CV} \geq 34.8 \%$ were at increased risk for LEA (both logrank $p<0.001$, Fig. 1).

Table 1 Comparisons of baseline sociodemographic factors, lifestyle behaviours, diabetes-related variables, drug-related variables, comorbidities and blood biochemical measurements according to LEA incidence in individuals with type 2 diabetes enrolled in the NDCMP, Taiwan

\begin{tabular}{|c|c|c|c|c|c|}
\hline \multirow[t]{2}{*}{ Variable } & \multicolumn{4}{|l|}{ LEA } & \multirow[t]{2}{*}{$p$ value } \\
\hline & $\operatorname{Minor}(n=310)$ & Major $(n=195)$ & Both $(n=36)$ & No $(n=27,033)$ & \\
\hline \multicolumn{6}{|l|}{ Sociodemographic factors } \\
\hline Male, $n(\%)$ & $155(50.00)$ & $97(49.74)$ & $22(61.11)$ & $12,112(44.8)$ & 0.03 \\
\hline Age (years), mean (SD) & $65.48(8.20)$ & $67.48(8.28)$ & $68.53(9.12)$ & $64.54(8.47)$ & $<0.001$ \\
\hline \multicolumn{6}{|l|}{ Lifestyle behaviours, $n(\%)$} \\
\hline Smoking & $53(17.10)$ & 37 (18.97) & $2(5.56)$ & $3515(13.00)$ & 0.006 \\
\hline Alcohol drinking & $17(5.48)$ & $13(6.67)$ & $2(5.56)$ & $1954(7.23)$ & 0.65 \\
\hline \multicolumn{6}{|l|}{ Diabetes-related variables } \\
\hline Diabetes duration (years), mean (SD) & $10.53(7.92)$ & $10.57(8.16)$ & $10.69(6.75)$ & $7.29(6.87)$ & $<0.001$ \\
\hline Type of glucose-lowering drug use, $n(\%)$ & & & & & $<0.001$ \\
\hline No medication & $1(0.32)$ & $0(0.00)$ & $0(0.00)$ & $469(1.73)$ & \\
\hline One glucose-lowering drug & $18(5.81)$ & $16(8.21)$ & $1(2.78)$ & $4684(17.33)$ & \\
\hline Two glucose-lowering drugs & $86(27.74)$ & $56(28.72)$ & $9(25.00)$ & $11,226(41.53)$ & \\
\hline Three glucose-lowering drugs & $53(17.1)$ & $35(17.95)$ & $7(19.44)$ & $4873(18.03)$ & \\
\hline$>3$ glucose-lowering drugs & $16(5.16)$ & $8(4.1)$ & $3(8.33)$ & $1378(5.1)$ & \\
\hline Insulin only & $24(7.74)$ & $15(7.69)$ & $2(5.56)$ & $755(2.79)$ & \\
\hline Insulin + glucose-lowering drug & $112(36.13)$ & $65(33.33)$ & $14(38.89)$ & $3648(13.49)$ & \\
\hline \multicolumn{6}{|l|}{ Drug-related variables, $n(\%)$} \\
\hline Hypertension drug treatment & $133(42.9)$ & $87(44.62)$ & $21(58.33)$ & $11,275(41.71)$ & 0.18 \\
\hline \multicolumn{6}{|l|}{ Comorbidities, $n(\%)$} \\
\hline Obesity $\left(\mathrm{BMI} \geq 27 \mathrm{~kg} / \mathrm{m}^{2}\right)$ & $106(34.19)$ & $56(28.72)$ & $11(30.56)$ & $9489(35.10)$ & 0.27 \\
\hline $\mathrm{CAD}$ & $34(10.97)$ & $18(9.23)$ & $6(16.67)$ & $2642(9.77)$ & 0.48 \\
\hline $\mathrm{CHF}$ & $12(3.87)$ & $13(6.67)$ & $2(5.56)$ & $777(2.87)$ & 0.008 \\
\hline Cancer & $8(2.58)$ & $8(4.1)$ & $1(2.78)$ & $603(2.23)$ & $0.24^{\mathrm{a}}$ \\
\hline Hyperlipidaemia & $75(24.19)$ & $55(28.21)$ & $6(16.67)$ & $6774(25.06)$ & 0.48 \\
\hline Hypertension & $174(56.13)$ & $117(60.00)$ & $26(72.22)$ & $13,402(49.58)$ & $<0.001$ \\
\hline Atrial fibrillation & $2(0.65)$ & $2(1.03)$ & $0(0)$ & $166(0.61)$ & $0.61^{\mathrm{a}}$ \\
\hline Stroke & $29(9.35)$ & $28(14.36)$ & $6(16.67)$ & $1574(5.82)$ & $<0.001$ \\
\hline COPD & $17(5.48)$ & $19(9.74)$ & $5(13.89)$ & $1364(5.05)$ & 0.002 \\
\hline Hypoglycaemia & $0(0.00)$ & $7(3.59)$ & $0(0)$ & $117(0.43)$ & $<0.001^{\mathrm{a}}$ \\
\hline CKD $\left(\mathrm{eGFR}<60 \mathrm{ml} \mathrm{min}{ }^{-1} 1.73 \mathrm{~m}^{-2}\right)$ & $140(45.16)$ & $111(56.92)$ & $15(41.67)$ & $8352(30.9)$ & $<0.001$ \\
\hline Diabetes-related retinopathy & $22(7.1)$ & $16(8.21)$ & $3(8.33)$ & $538(1.99)$ & $<0.001^{\mathrm{a}}$ \\
\hline Peripheral neuropathy & $9(2.9)$ & $0(0)$ & $1(2.78)$ & $244(0.9)$ & $0.004^{\mathrm{a}}$ \\
\hline PAD & $11(3.55)$ & $10(5.13)$ & $1(2.78)$ & $670(2.48)$ & $0.07^{\mathrm{a}}$ \\
\hline Foot ulcer & $8(2.58)$ & $3(1.54)$ & $2(5.56)$ & $71(0.26)$ & $<0.001^{\mathrm{a}}$ \\
\hline \multicolumn{6}{|l|}{ Blood biochemical measurements, mean (SD) } \\
\hline Mean FPG (mmol/l) & $10.77(3.29)$ & $10.37(3.21)$ & $10.93(3.93$ & $9.24(2.67)$ & $<0.001$ \\
\hline Mean $\mathrm{HbA}_{\mathrm{lc}}(\mathrm{mmol} / \mathrm{mol})[\%]$ & $\begin{array}{c}75.60(18.56) \\
{[9.07(1.70)]}\end{array}$ & $\begin{array}{r}70.83(19.00) \\
\quad[8.63(1.74)]\end{array}$ & $\begin{array}{r}74.63(22.67) \\
{[8.98(2.07)]}\end{array}$ & $\begin{array}{l}63.18(16.84) \\
{[7.93(1.54)]}\end{array}$ & $<0.001$ \\
\hline $\mathrm{eGFR}\left(\mathrm{ml} \mathrm{min} \min ^{-1} 1.73 \mathrm{~m}^{-2}\right)$ & $63.24(24.20)$ & $55.02(24.16)$ & $59.32(23.84)$ & $70.37(20.85)$ & $<0.001$ \\
\hline Number of FPG & $2.91(0.88)$ & $3.11(0.93)$ & $3.11(0.98)$ & $3.07(0.95)$ & 0.03 \\
\hline Number of $\mathrm{HbA}_{\mathrm{lc}}$ & $3.24(1.30)$ & $3.47(1.30)$ & $3.25(1.30)$ & $3.45(1.39)$ & 0.05 \\
\hline
\end{tabular}

Differences in continuous variables were tested using one-way ANOVA. Differences in categorical variables were tested using the $\chi^{2}$ test

${ }^{a}$ Fisher's exact test

$\mathrm{CAD}$, coronary artery disease 


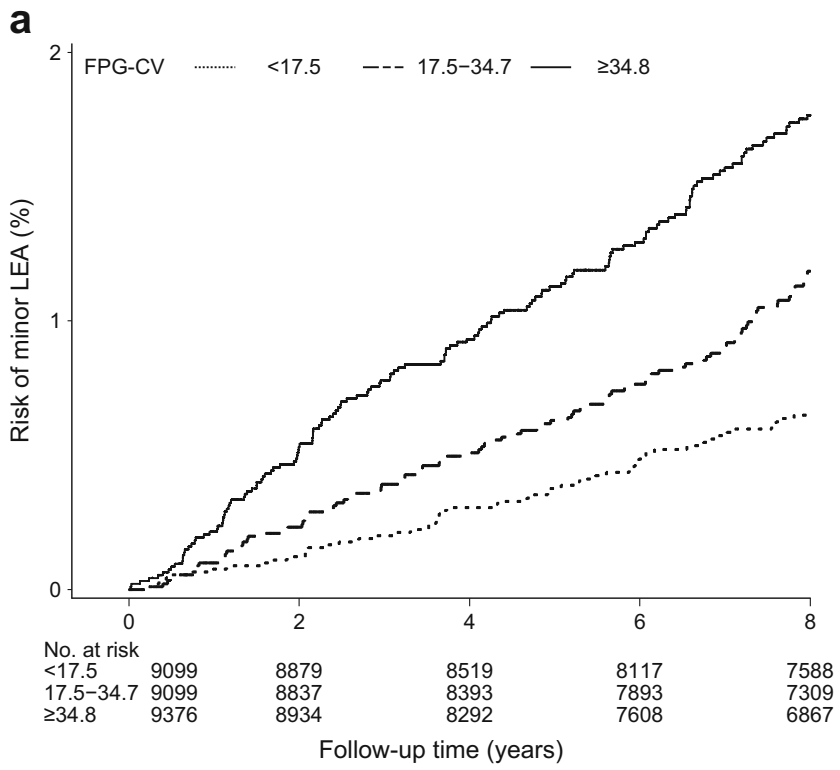

b

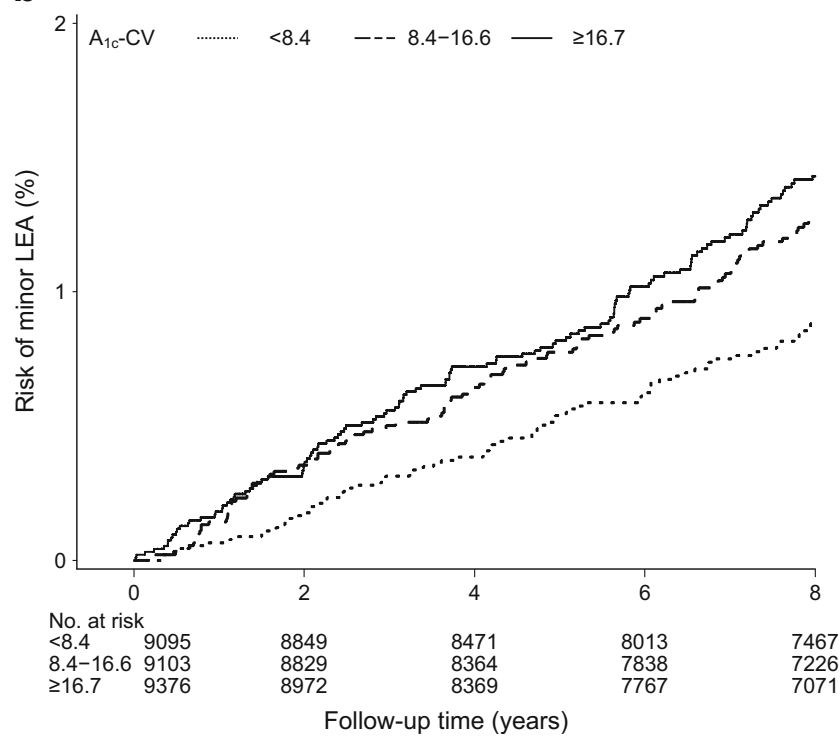

Fig. 1 Risks of minor LEA over time for (a) FPG-CV and (b) $\mathrm{A}_{1 \mathrm{c}}-\mathrm{CV}$

Table 2 shows the crude incidence density rates and HRs of minor and major LEA for the tertile subgroups of FPG-CV, $\mathrm{A}_{1 \mathrm{c}}-\mathrm{CV}, \mathrm{FPG}-\mathrm{ARV}$ and $\mathrm{A}_{1 \mathrm{c}}-\mathrm{ARV}$. The minor LEA risk of individuals in the third tertile subgroup of FPG-CV was significant (adjusted HR 1.53 [1.15, 2.04], $p=0.004$ ) after adjusting for all covariates. Similarly, individuals in the third tertile of $\mathrm{A}_{1 \mathrm{c}} \mathrm{C}-\mathrm{CV}$ manifested a significant increase in minor LEA risk (adjusted HR $1.34[1.02,1.77], p=0.04$ ). The minor LEA risk of individuals in the third tertile subgroup of FPGARV was significant (adjusted HR 1.78 [1.33, 2.38], $p<0.001$ ) after adjusting for all covariates. By contrast, $\mathrm{A}_{1 c^{-}}$ ARV was not significantly associated with minor LEA. After using restricted cubic splines, a non-linear association was found for FPG-CV and $\mathrm{A}_{1 \mathrm{c}}-\mathrm{CV}$ with the risk of LEA (Fig.
2). All four glycaemic variability measures were not associated with major LEA. The HRs of minor LEA for all factors considered in the final models are presented in ESM Table 2.

Considering that $\mathrm{FPG}-\mathrm{CV}$ and $\mathrm{A}_{1 \mathrm{c}}-\mathrm{CV}$ were more sensitive in capturing the associations with minor LEA, further analyses focused on the associations of these two glucose variation measures with minor LEA. We excluded individuals with existing comorbidities from sensitivity analyses to rule out the potential bias, including hyperglycaemic hyperosmolar nonketotic coma, diabetes-related ketoacidosis $(n=653)$, hypoglycaemia $(n=124)$, peripheral neuropathy $(n=254)$, foot ulcer $(n=84)$ and all comorbidities $(n=1140)$. Individuals with FPG-CV of $\geq 34.8 \%$ exhibited a similar significant HR for minor LEA of $1.49(1.10,2.01 ; p=0.01)$, and the effect of A1C-CV was also significant $(1.36$ [1.02, 1.81], $p=0.04$ ) (Table 3). When no adjustment was made for foot ulcers, our study results remained similar. We also evaluated whether the cut-off point values affected our findings by categorising FPG-CV and $\mathrm{A}_{1 \mathrm{c}}-\mathrm{CV}$ at $20 \%$ and $35 \%$ and found similar results (ESM Table 3). A total of 46,628 people were included after multiple imputation for missing data. The adjusted HRs estimated were similar to those that used the complete dataset (ESM Table 4).

The interactions of FPG-CV and $\mathrm{A}_{1 \mathrm{c}}-\mathrm{CV}$ with diabetes duration and $\mathrm{CKD}$ status were examined to determine whether the magnitudes of the associations of FPG-CV and $\mathrm{A}_{1 \mathrm{c}}-\mathrm{CV}$ with minor LEA risk differ according to diabetes duration and renal function. We found significant interaction effects $(p<0.01$ for FPG-CV with diabetes duration and borderline significance for $\mathrm{A}_{1 \mathrm{c}} \mathrm{CV}$ with renal function, $p=0.13$ ). Thus, we further explored the effects of FPG-CV and $\mathrm{A}_{1 \mathrm{c}} \mathrm{-CV}$ stratified by diabetes duration (Table 4) and renal function (ESM Fig. 3). We found that the multivariate-adjusted HRs for the second and third FPG-CV tertiles were significantly linked to minor LEA in individuals with more than 3 years of diabetes duration $(1.53$ [1.07, 2.18], $p=0.02$; and 1.94 [1.38, 2.72], $p<0.001$, respectively) but not in those with diabetes duration of less than 3 years. The third $\mathrm{A}_{1 \mathrm{c}}-\mathrm{CV}$ tertile was also significantly correlated with minor LEA risk only in individuals with more than 3 years of diabetes duration (1.51 [1.12, $2.05], p=0.008$ ). For the stratification analysis of renal function status, we observed that multivariate-adjusted HRs in the third FPG-CV and $\mathrm{A}_{1 \mathrm{c}}-\mathrm{CV}$ tertiles were significantly linked to minor LEA in individuals with eGFR $\geq 60 \mathrm{ml} \mathrm{min}^{-1} 1.73 \mathrm{~m}^{-2}$ $(1.52[1.04,2.22], p=0.03$; and $1.47[1.02,2.11], p=0.04$, respectively).

\section{Discussion}

On the basis of the analysis of a large nationwide cohort of 27,574 Taiwan Diabetes Study enrolees with type 2 diabetes mellitus, this observational study first showed that high levels 
Table 2 HRs of LEA according to the tertiles of FPG-CV, $\mathrm{A}_{1 \mathrm{c}}-\mathrm{CV}, \mathrm{FPG}-\mathrm{ARV}$ and $\mathrm{A}_{1 \mathrm{c}}-\mathrm{ARV}$ in individuals with type 2 diabetes

\begin{tabular}{|c|c|c|c|c|c|c|c|c|c|c|}
\hline \multirow[t]{3}{*}{ Variable } & \multirow[t]{3}{*}{$n$} & \multirow[t]{3}{*}{ Cases } & \multirow[t]{3}{*}{ Person-years } & \multirow[t]{3}{*}{$\operatorname{IR}(95 \% \mathrm{CI})^{\mathrm{a}}$} & & & \multicolumn{2}{|l|}{ LEA } & & \\
\hline & & & & & \multicolumn{2}{|l|}{ Model I } & \multicolumn{2}{|l|}{ Model II } & \multicolumn{2}{|l|}{ Model III } \\
\hline & & & & & HR $(95 \%$ CI) & $p$ value & $\operatorname{HR}(95 \% \mathrm{CI})$ & $p$ value & $\mathrm{HR}(95 \% \mathrm{CI})$ & $p$ value \\
\hline \multicolumn{11}{|l|}{ Minor LEA } \\
\hline \multicolumn{11}{|l|}{ FPG-CV (\%) } \\
\hline$<17.5$ & 9099 & 69 & 76,157 & $0.91(0.69,1.12)$ & 1.00 & & 1.00 & & 1.00 & \\
\hline $17.5-34.7$ & 9099 & 112 & 75,133 & $1.49(1.21,1.77)$ & $1.65(1.22,2.23)$ & 0.001 & $1.38(1.02,1.86)$ & 0.04 & $1.30(0.96,1.76)$ & 0.09 \\
\hline$\geq 34.8$ & 9376 & 165 & 73,377 & $2.25(1.91,2.59)$ & $2.53(1.91,3.35)$ & $<0.001$ & $1.71(1.28,2.28)$ & $<0.001$ & $1.53(1.15,2.04)$ & 0.004 \\
\hline$p_{\text {trend }}$ & & & & & $<0.001$ & & $<0.001$ & & 0.004 & \\
\hline \multicolumn{11}{|l|}{$\mathrm{A}_{1 \mathrm{c}^{-} \mathrm{CV}(\%)}$} \\
\hline$<8.4$ & 9095 & 84 & 75,487 & $1.11(0.87,1.35)$ & 1.00 & & 1.00 & & 1.00 & \\
\hline $8.4-16.6$ & 9103 & 120 & 74,911 & $1.60(1.32,1.89)$ & $1.45(1.09,1.91)$ & 0.01 & $1.26(0.95,1.67)$ & 0.10 & $1.16(0.87,1.53)$ & 0.31 \\
\hline$\geq 16.7$ & 9376 & 142 & 74,269 & $1.91(1.60,2.23)$ & $1.73(1.32,2.27)$ & $<0.001$ & $1.53(1.16,2.01)$ & 0.003 & $1.34(1.02,1.77)$ & 0.04 \\
\hline$p_{\text {trend }}$ & & & & & $<0.001$ & & 0.002 & & 0.04 & \\
\hline \multicolumn{11}{|c|}{ FPG-ARV (\%) } \\
\hline$<17.3$ & 9099 & 65 & 76,162 & $0.85(0.65,1.06)$ & 1.00 & & 1.00 & & 1.00 & \\
\hline $17.3-35.8$ & 9098 & 104 & 74,897 & $1.39(1.12,1.66)$ & $1.63(1.202 .23)$ & 0.002 & $1.38(1.01,1.88)$ & 0.05 & $1.31(0.96,1.79)$ & 0.09 \\
\hline$\geq 35.9$ & 9377 & 177 & 73,608 & $2.40(2.05,2.76)$ & $2.87(2.16,3.82)$ & $<0.001$ & $1.96(1.47,2.63)$ & $<0.001$ & $1.78(1.33,2.38)$ & $<0.001$ \\
\hline$p_{\text {trend }}$ & & & & & $<0.001$ & & $<0.001$ & & $<0.001$ & \\
\hline \multicolumn{11}{|c|}{$\mathrm{A}_{1 \mathrm{c}}-\mathrm{ARV}(\%)$} \\
\hline$<7.8$ & 9099 & 91 & 75,629 & $1.20(0.96,1.45)$ & 1.00 & & 1.00 & & 1.00 & \\
\hline $7.8-16.1$ & 9100 & 121 & 74,660 & $1.62(1.33,1.91)$ & $1.35(1.03,1.78)$ & 0.03 & $1.21(0.92,1.59)$ & 0.17 & $1.14(0.86,1.49)$ & 0.36 \\
\hline$\geq 16.2$ & 9375 & 134 & 74,379 & $1.80(1.50,2.11)$ & $1.51(1.15,1.97)$ & 0.003 & $1.34(1.02,1.76)$ & 0.04 & $1.20(0.91,1.57)$ & 0.20 \\
\hline$p_{\text {trend }}$ & & & & & 0.003 & & 0.03 & & 0.21 & \\
\hline \multicolumn{11}{|l|}{ Major LEA } \\
\hline \multicolumn{11}{|l|}{ FPG-CV (\%) } \\
\hline$<17.5$ & 9099 & 55 & 76,196 & $0.72(0.53,0.91)$ & 1.00 & & 1.00 & & 1.00 & \\
\hline $17.5-34.7$ & 9099 & 77 & 75,282 & $1.02(0.79,1.25)$ & $1.45(1.02,2.05)$ & 0.04 & $1.21(0.85,1.71)$ & 0.29 & $1.13(0.79,1.60)$ & 0.51 \\
\hline$\geq 34.8$ & 9376 & 99 & 73,730 & $1.34(1.08,1.61)$ & $1.92(1.38,2.67)$ & $<0.001$ & $1.31(0.93,1.83)$ & 0.12 & $1.13(0.80,1.59)$ & 0.48 \\
\hline$p_{\text {trend }}$ & & & & & $<0.001$ & & 0.13 & & 0.51 & \\
\hline \multicolumn{11}{|l|}{$\mathrm{A}_{1 \mathrm{c}}-\mathrm{CV}(\%)$} \\
\hline$<8.4$ & 9095 & 67 & 75,605 & $0.89(0.67,1.10)$ & 1.00 & & 1.00 & & 1.00 & \\
\hline $8.4-16.6$ & 9103 & 73 & 75,143 & $0.97(0.75,1.19)$ & $1.11(0.80,1.55)$ & 0.54 & $0.98(0.70,1.37)$ & 0.91 & $0.87(0.62,1.21)$ & 0.40 \\
\hline$\geq 16.7$ & 9376 & 91 & 74,460 & $1.22(0.97,1.47)$ & $1.42(1.04,1.95)$ & 0.03 & $1.26(0.92,1.74)$ & 0.16 & $1.05(0.76,1.45)$ & 0.78 \\
\hline \multirow{2}{*}{\multicolumn{11}{|c|}{$\begin{array}{l}p_{\text {trend }} \\
\text { FPG-ARV (\%) }\end{array}$}} \\
\hline & & & & & & & & & & \\
\hline$<17.3$ & 9099 & 51 & 76,217 & $0.67(0.49,0.85)$ & 1.00 & & 1.00 & & 1.00 & \\
\hline $17.3-35.8$ & 9098 & 73 & 75,033 & $0.97(0.75,1.20)$ & $1.49(1.04,2.13)$ & 0.03 & $1.26(0.88,1.80)$ & 0.21 & $1.19(0.83,1.70)$ & 0.35 \\
\hline$\geq 35.9$ & 9377 & 107 & 73,958 & $1.45(1.17,1.72)$ & $2.23(1.60,3.12)$ & $<0.001$ & $1.54(1.09,2.17)$ & 0.01 & $1.33(0.94,1.88)$ & 0.10 \\
\hline$p_{\text {trend }}$ & & & & & $<0.001$ & & 0.01 & & 0.10 & \\
\hline \multicolumn{11}{|c|}{$\mathrm{A}_{1 \mathrm{c}}-\mathrm{ARV}(\%)$} \\
\hline$<7.8$ & 9099 & 68 & 75,741 & $0.90(0.68,1.11)$ & 1.00 & & 1.00 & & 1.00 & \\
\hline $7.8-16.1$ & 9100 & 75 & 74,902 & $1.00(0.77,1.23)$ & $1.13(0.81,1.57)$ & 0.47 & $1.02(0.73,1.41)$ & 0.92 & $0.91(0.65,1.27)$ & 0.58 \\
\hline$\geq 16.2$ & 9375 & 88 & 74,564 & $1.18(0.93,1.43)$ & $1.36(0.99,1.86)$ & 0.06 & $1.21(0.88,1.67)$ & 0.25 & $1.02(0.74,1.41)$ & 0.91 \\
\hline$p_{\text {trend }}$ & & & & & 0.06 & & 0.23 & & 0.87 & \\
\hline
\end{tabular}

Model I adjusted for age and sex

Model II adjusted for age, sex, smoking, alcohol consumption, diabetes duration, type of glucose-lowering drugs and hypertension drug treatment Model III adjusted for age, sex, smoking, alcohol consumption, diabetes duration, type of hypoglycaemic drug, hypertension drug treatment, mean level of FPG, mean level of $\mathrm{HbA}_{1 \mathrm{c}}$, obesity, coronary artery disease, CHF, cancer, hyperlipidaemia, hypertension, atrial fibrillation, stroke, COPD, hypoglycaemia, $\mathrm{CKD}$, diabetes-related retinopathy, peripheral neuropathy, PAD and foot ulcer

${ }^{a}$ Exact CIs for Poisson distribution

IR, incidence density rate (number of incident cases/person-years $\times 1000$ )

of visit-to-visit FPG and $\mathrm{HbA}_{1 \mathrm{c}}$ variabilities defined by $\mathrm{CVs}$ were linked to increased minor LEA risk. These associations remained significant after adjustments were made for baseline FPG and $\mathrm{HbA}_{1 \mathrm{c}}$ and traditional risk factors. Both FPG-CV and $\mathrm{A}_{1 \mathrm{c}}-\mathrm{CV}$ exerted independent effects on minor LEA risk. After excluding individuals with comorbidities and acute complications, our findings demonstrated similar associations of FPG-CV and $\mathrm{A}_{1 \mathrm{c}}-\mathrm{CV}$ with minor LEA risks. In addition, diabetes duration modified the associations of FPG-CV and $\mathrm{A}_{1 \mathrm{c}}-\mathrm{CV}$ with minor LEA risk. Amongst individuals with more than 3 years of diabetes duration, those with FPG-CV $\geq 34.8 \%$ and $A_{1 c}-C V \geq 16.7 \%$ had increased minor LEA risks of $95 \%$ 
a

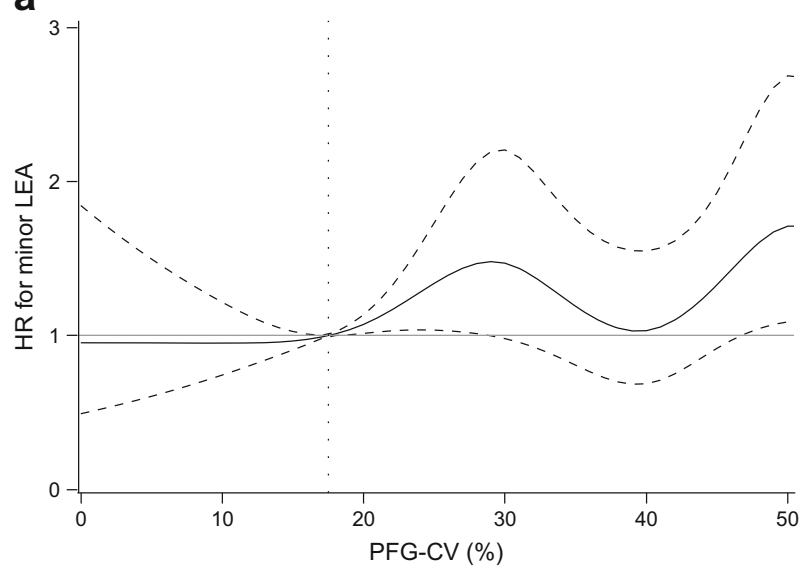

b

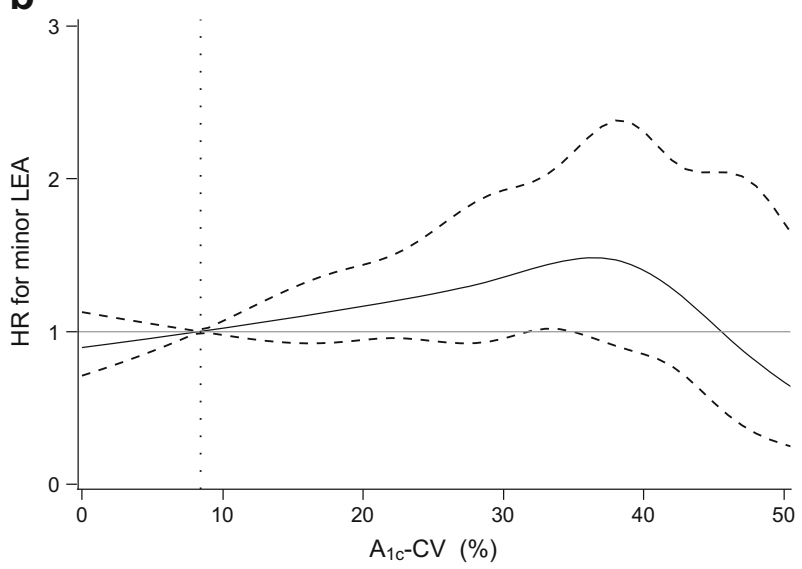

Fig. 2 Restricted multivariable cubic spline plots (with 95\% CI) for (a) FPG$\mathrm{CV}$ and (b) $\mathrm{A}_{1 \mathrm{c}}-\mathrm{CV}$. The reference value (i.e. the cut-off point for the first tertile) for FPG-CV was set at $17.5 \%$ and for $\mathrm{A}_{1 \mathrm{c}}-\mathrm{CV}$ at $8.4 \%$. The HRs were adjusted for age, sex, smoking, alcohol consumption, diabetes duration, type of hypoglycaemic drug, hypertension drug treatment, FPG, $\mathrm{HbA}_{1 \mathrm{c}}$, obesity, coronary artery disease, CHF, cancer, hyperlipidaemia, hypertension, atrial fibrillation, stroke, chronic hepatitis, COPD, hypoglycaemia, CKD, diabetes-related retinopathy, peripheral neuropathy, $\mathrm{PAD}$ and foot ulcer

and 52\%, respectively. We observed significant FPG-CV and $A_{1 c}-C V$ effects on LEA only in individuals with eGFR $\geq$ $60 \mathrm{ml} \mathrm{min}^{-1} 1.73 \mathrm{~m}^{-2}$.

Oscillatory plasma glucose is more detrimental than stable high glucose in inflammation, insulin resistance, generation of oxidative stress, vascular endothelial dysfunction, atherosclerosis progression and hyperglycaemia-related downstream consequences [21]. The mechanisms for the link between visit-tovisit FPG and $\mathrm{HbA}_{1 \mathrm{c}}$ variabilities and LEA remain to be elucidated, but can be explained by three possible mechanisms. First, the interactions of inflammation and oxidative stress in the development of diabetes-related atherosclerosis may be the underlying mechanisms of glycaemic variability that are associated with LEA [22]. Hyperglycaemia, resulting in high variation in plasma glucose, is usually accompanied by inflammation and oxidative stress. Hyperglycaemia induces the production of mitochondrial reactive oxygen species and results in the formation of intracellular advanced glycation endproducts [23]. Reactive oxygen species directly increase inflammatory expression and insulin resistance [24]. Moreover, all factors contributing to hypertension have a unifying feature, oxidative stress [25], which is a risk factor for atherosclerosis. Second, glycaemic variability might be a proxy for multiple morbidities, which may have played a role in the link to LEA risk. Individuals with multi-morbidities experience difficulties in managing multiple medications and poor coordination of multiple medical care providers [26]. The mean number of chronic conditions in individuals with diabetes is 3.4 , and these individuals face high demands on their time to manage their chronic conditions [27]. To rule out this possibility, we excluded individuals who suffered from chronic conditions at baseline, and the risk estimates for glycaemic variability remained similar to the original. Third, individuals with greater glycaemic variation are more likely to have neuropathy and/ or ischaemia that is more susceptible to ulceration and infection, which are potential risk factors of amputation [28, 29].

Our study was the first and largest cohort study to display the independent relationships of visit-to-visit $\mathrm{FPG}$ and $\mathrm{HbA}_{1 \mathrm{c}}$ variabilities with minor LEA risk in older individuals with type 2 diabetes. FPG and $\mathrm{HbA}_{1 \mathrm{c}}$ were measured during follow-up care in routine clinical settings as a part of managed care in Taiwan and many other countries. Considering the availability of electronic computerised systems, deriving visit-to-visit FPG and $\mathrm{HbA}_{1 \mathrm{c}}$ variabilities in routine clinical practice is becoming feasible. Further studies are needed to support our findings and to determine the optimal treatment option for older individuals with type 2 diabetes and high glycaemic variability.

Several limitations should be noted. First, the design is observational. Thus, the confounding effects of some covariates without adjustment or residual confounding may exist. We made our best effort to adjust for as many confounders as possible to minimise the potential confounding effects. We also adopted a restriction strategy to exclude the confounding effects of comorbidities in sensitivity analysis by excluding those with specific comorbidities to eliminate their effects on study findings. The presence of comorbidities was associated with increased risk of minor LEA, which may confound the relationship between glycaemic variability and minor LEA risk. The multivariate adjustment for control of confounding effects may not be adequate, because the prevalence for these comorbidities was low. A restriction approach can increase the homogeneity of the study subjects and enhance the interval validity of our study findings. Our findings remained similar, indicating that our study findings are robust. Second, our study population included individuals with type 2 diabetes enrolled in the NDCMP. To assess the representativeness of the study population, we checked the age and sex distributions in our study population against those for the entire Taiwan population with type 2 diabetes for the same period. We found similar distributions, which indicated the generalisability of our findings. Our 


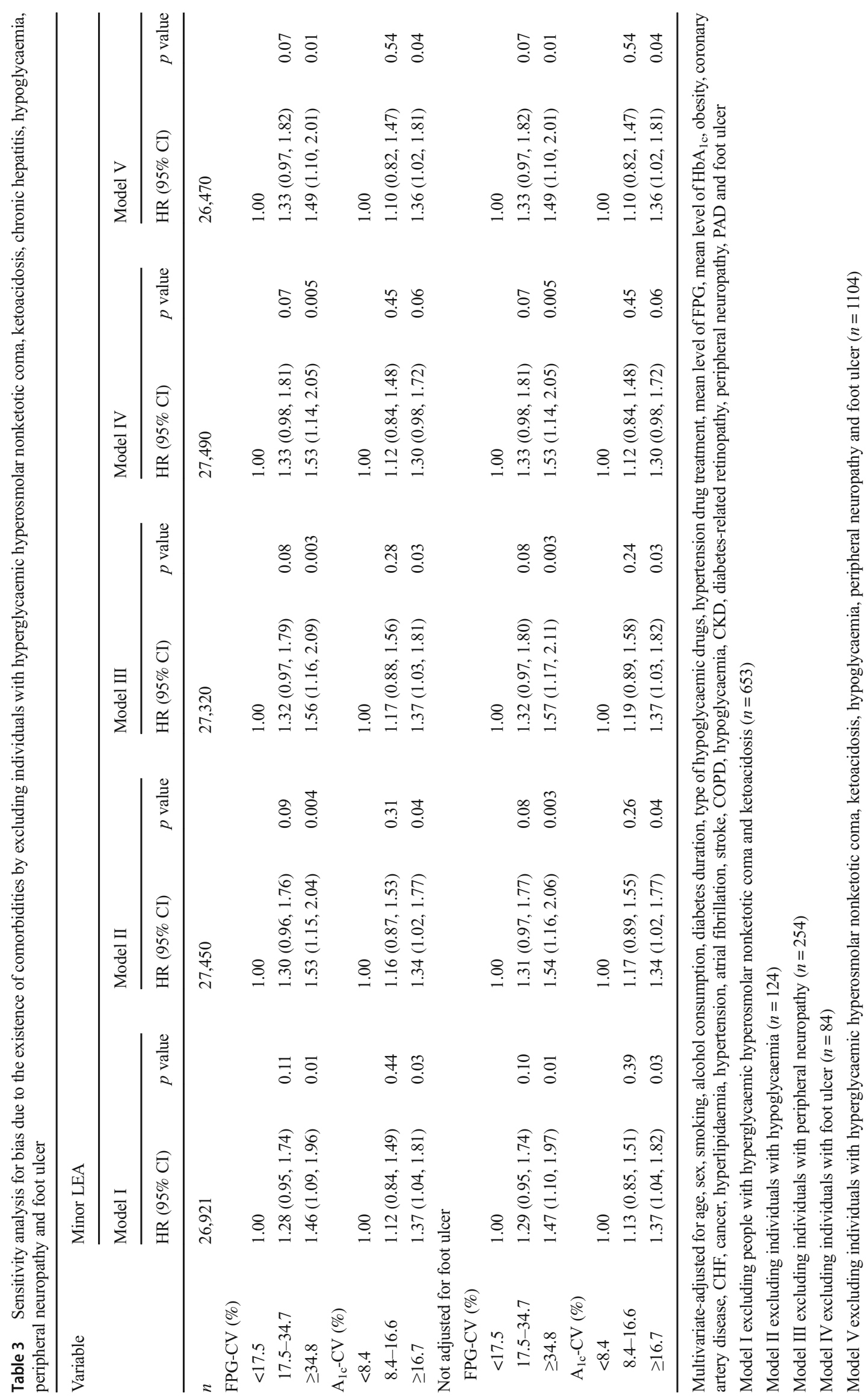


Table 4 HRs of minor LEA according to the tertiles of FPG-CV and $\mathrm{A}_{1 \mathrm{c}}-\mathrm{CV}$ in individuals with type 2 diabetes stratified by diabetes duration

\begin{tabular}{|c|c|c|c|c|c|c|c|c|}
\hline \multirow[t]{3}{*}{ Variable } & \multicolumn{8}{|l|}{ Minor LEA } \\
\hline & \multicolumn{2}{|l|}{ Model I } & \multicolumn{2}{|l|}{ Model II } & \multicolumn{2}{|c|}{$\begin{array}{l}\text { Model III (Not adjustment } \\
\text { for foot ulcer) }\end{array}$} & \multicolumn{2}{|l|}{ Model IV } \\
\hline & $\mathrm{HR}(95 \% \mathrm{CI})$ & $p$ value & $\mathrm{HR}(95 \% \mathrm{CI})$ & $p$ value & $\mathrm{HR}(95 \% \mathrm{CI})$ & $p$ value & $\operatorname{HR}(95 \% \mathrm{CI})$ & $p$ value \\
\hline \multicolumn{9}{|c|}{ Diabetes duration $\leq 3$ years $(n=10,059)$} \\
\hline \multicolumn{9}{|c|}{ FPG-CV $(\%)$} \\
\hline$<17.5$ & 1.00 & & 1.00 & & 1.00 & & 1.00 & \\
\hline $17.5-34.7$ & $1.07(0.58,1.97)$ & 0.84 & $0.88(0.48,1.64)$ & 0.70 & $0.81(0.43,1.50)$ & 0.50 & $0.81(0.44,1.51)$ & 0.51 \\
\hline$\geq 34.8$ & $1.20(0.66,2.19)$ & 0.54 & $0.77(0.42,1.43)$ & 0.41 & $0.64(0.34,1.18)$ & 0.15 & $0.62(0.33,1.17)$ & 0.14 \\
\hline$p_{\text {trend }}$ & 0.55 & & 0.41 & & 0.15 & & 0.14 & \\
\hline \multicolumn{9}{|l|}{$\mathrm{A}_{1 \mathrm{c}}-\mathrm{CV}(\%)$} \\
\hline$<8.4$ & 1.00 & & 1.00 & & 1.00 & & 1.00 & \\
\hline $8.4-16.6$ & $1.40(0.73,2.69)$ & 0.31 & $1.16(0.61,2.24)$ & 0.65 & $1.02(0.53,1.97)$ & 0.96 & $1.06(0.54,2.05)$ & 0.87 \\
\hline$\geq 16.7$ & $1.33(0.71,2.50)$ & 0.37 & $0.95(0.50,1.79)$ & 0.87 & $0.72(0.38,1.39)$ & 0.33 & $0.76(0.39,1.47)$ & 0.41 \\
\hline$p_{\text {trend }}$ & 0.40 & & 0.80 & & 0.28 & & 0.35 & \\
\hline \multicolumn{9}{|c|}{ Diabetes duration $>3$ years $(n=17,515)$} \\
\hline \multicolumn{9}{|c|}{ FPG-CV $(\%)$} \\
\hline$<17.5$ & 1.00 & & 1.00 & & 1.00 & & 1.00 & \\
\hline $17.5-34.7$ & $1.81(1.27,2.57)$ & 0.001 & $1.61(1.13,2.29)$ & 0.009 & $1.53(1.08,2.18)$ & 0.02 & $1.53(1.07,2.18)$ & 0.02 \\
\hline$\geq 34.8$ & $2.91(2.10,4.05)$ & $<0.001$ & $2.13(1.52,2.98)$ & $<0.001$ & $1.95(1.39,2.74)$ & $<0.001$ & $1.94(1.38,2.72)$ & $<0.001$ \\
\hline$p_{\text {trend }}$ & $<0.001$ & & $<0.001$ & & $<0.001$ & & $<0.001$ & \\
\hline \multicolumn{9}{|l|}{$\mathrm{A}_{1 \mathrm{c}}-\mathrm{CV}(\%)$} \\
\hline$<8.4$ & 1.00 & & 1.00 & & 1.00 & & 1.00 & \\
\hline $8.4-16.6$ & $1.44(1.06,1.96)$ & 0.02 & $1.28(0.94,1.75)$ & 0.12 & $1.20(0.88,1.64)$ & 0.25 & $1.18(0.86,1.60)$ & 0.31 \\
\hline$\geq 16.7$ & $1.97(1.46,2.66)$ & $<0.001$ & $1.70(1.26,2.30)$ & $<0.001$ & $1.53(1.13,2.07)$ & 0.007 & $1.51(1.12,2.05)$ & 0.008 \\
\hline$p_{\text {trend }}$ & $<0.001$ & & $<0.001$ & & 0.006 & & 0.006 & \\
\hline
\end{tabular}

Model I adjusted for age and sex

Model II adjusted for age, sex, smoking, alcohol consumption, diabetes duration, type of glucose-lowering drugs and hypertension drug treatment

Model III adjusted for age, sex, smoking, alcohol consumption, diabetes duration, type of hypoglycaemic drug, hypertension drug treatment, mean level of FPG, mean level of $\mathrm{HbA}_{1 \mathrm{c}}$, obesity, coronary artery disease, CHF, cancer, hyperlipidaemia, hypertension, atrial fibrillation, stroke, COPD, hypoglycaemia, $\mathrm{CKD}$, diabetes-related retinopathy, peripheral neuropathy and PAD

Model IV adjusted for age, sex, smoking, alcohol consumption, diabetes duration, type of hypoglycaemic drug, hypertension drug treatment, mean level of FPG, mean level of $\mathrm{HbA}_{1 \mathrm{c}}$, obesity, coronary artery disease, CHF, cancer, hyperlipidaemia, hypertension, atrial fibrillation, stroke, COPD, hypoglycaemia, $\mathrm{CKD}$, diabetes-related retinopathy, peripheral neuropathy, PAD and foot ulcer

findings can also be generalised to a population with type 2 diabetes that has similar characteristics to ours. Third, we did not apply time-varying proportional hazards models due to the unavailability of the NDCMP database for deriving glucose variation for subsequent years of follow-up blood tests. We only had NDCMP datasets for 2002-2004, which allowed us to derive 1 year glucose variability measures for those who had been followed up for more than 1 year during this period as baseline measures. Fourth, the mean value for the number of outpatient visits within 1 year is about 3 , which is less than 4 , the expected mean number under the guidelines of NDCMP in Taiwan for diabetes outpatient care. These mean values, in general, are consistent with guideline regulations. Although the data on glucose variability in this analysis are limited, they still can capture the association between glucose variability and minor LEA. After thorough evaluation of potential bias, our study's findings remain similar, indicating the robustness of the results. A future study measuring glucose variability over a longer period and with more outpatient visits is needed to verify our study findings. Fifth, the results of the restricted multivariable cubic spline plot for $\mathrm{A}_{1 \mathrm{c}} \mathrm{CV}$ indicate that the $\mathrm{CI}$ of the $\mathrm{HR}$ for $\mathrm{A}_{1 \mathrm{c}}-\mathrm{CV} \geq 45 \%$ was wide, and the HR went down to 1 , which implied that the number of individuals with $\mathrm{A}_{1 \mathrm{c}}-\mathrm{CV} \geq 45 \%$ was not large enough ( $n=1331,4.95 \%)$ or its effect had a high variation. 
By categorising $\mathrm{A}_{1 \mathrm{c}}-\mathrm{CV}$ on the basis of tertiles, individuals with $A_{1 c}-C V \geq 45 \%$ were classified into the third category because the cut-off point value for the third tertile was $16.7 \%$. Given the small number of individuals with $\mathrm{A}_{1 \mathrm{c}}-\mathrm{CV} \geq 45 \%$, our study was not able to detect its effect. By considering those with $\mathrm{A}_{1 c^{-}}$ $\mathrm{CV} \geq 45 \%$ and those with $16.7 \%-45 \%$ together, we underestimated the effect of the third category for $\mathrm{A}_{1 \mathrm{c}}-\mathrm{CV}$, which was a minor threat to the validity of our findings. Finally, misclassification in the variation of glucose levels might be possible because of variation due to inter-clinical settings and accuracy. However, no evidence showed that this type of measurement error was differential. If an association existed between glucose variation and minor LEA, the non-differential misclassification error may underestimate the effect, which is a minor threat to the validity of our findings.

Several studies have identified the risk factors associated with LEA [2-7]. However, most of these studies were conducted in individuals with diabetes-related foot ulcers [29-32] or foot syndrome [33]. Few studies have been performed in individuals with diabetes $[6,34,35]$, which could provide clues about LEA prevention for a broader spectrum of the population with diabetes. Moreover, these studies focused on glucose control status, but none of them explored the potential effects of glycaemic variation on LEA. Therefore, our findings provide new insights into the adverse effects of visitto-visit $\mathrm{HbA}_{1 \mathrm{c}}$ and FPG variations on minor LEA in older individuals with type 2 diabetes and suggest that older individuals with type 2 diabetes and high visit-to-visit variations in $\mathrm{HbA}_{1 \mathrm{c}}$ and FPG are more likely to have minor LEA incidence.

Our study was the first to demonstrate that $\mathrm{FPG}$ and $\mathrm{HbA}_{1 \mathrm{c}}$ variabilities are associated with incident minor LEA risk. Older individuals who have had diabetes for more than 3 years are at substantial risk of minor LEA.

Data availability The datasets analysed during the current study are available from the corresponding author on reasonable request.

Funding This study was supported primarily by the Bureau of National Health Insurance (DOH94-NH-1007), the Ministry of Science and Technology of Taiwan (MOST 104-2314-B-039-016, MOST 105-2314B-039-021-MY3, MOST 105-2314-B-039-025-MY3, MOST 107-2314B-039-049, MOST 108-2314-B-039-039, MOST 108-2314-B-039-035MY3 and MOST 108-2314-B-039-031-MY2) and China Medical University Hospital (DMR-108-120).

Duality of interest The authors declare that there is no duality of interest associated with this manuscript.

Contribution statement TCL and CCL were responsible for the conception and design of the study. TCL and SYY acquired the data and CIL analysed the data. HMC, CSL, WYL, CHL and MCW interpreted the data. CIL and TCL were responsible for drafting the article. All authors revised the manuscript and approved the final version. TCL and CCL are responsible for the integrity of the work as a whole.

\section{References}

1. Cho N, Shaw J, Karuranga S et al (2018) IDF diabetes atlas: global estimates of diabetes prevalence for 2017 and projections for 2045 . Diabetes Res Clin Pract 138:271-281. https://doi.org/10.1016/j. diabres.2018.02.023

2. Boyko EJ, Ahroni JH, Stensel V, Forsberg RC, Davignon DR, Smith DG (1999) A prospective study of risk factors for diabetic foot ulcer. The Seattle Diabetic Foot Study. Diabetes Care 22(7): 1036-1042. https://doi.org/10.2337/diacare.22.7.1036

3. Winkley K, Stahl D, Chalder T, Edmonds ME, Ismail K (2007) Risk factors associated with adverse outcomes in a populationbased prospective cohort study of people with their first diabetic foot ulcer. J Diabetes Complicat 21(6):341-349. https://doi.org/10. 1016/j.jdiacomp.2007.09.004

4. Alvarsson A, Sandgren B, Wendel C, Alvarsson M, Brismar K (2012) A retrospective analysis of amputation rates in diabetic patients: can lower extremity amputations be further prevented? Cardiovasc Diabetol 11(1):18. https://doi.org/10.1186/1475-284011-18

5. Lacle A, Valero-Juan LF (2012) Diabetes-related lower-extremity amputation incidence and risk factors: a prospective seven-year study in Costa Rica. Rev Panam Salud Publica 32(3):192-198. https://doi.org/10.1590/S1020-49892012000900004

6. Humphrey AR, Dowse GK, Thoma K, Zimmet PZ (1996) Diabetes and nontraumatic lower extremity amputations. Incidence, risk factors, and prevention - a 12-year follow-up study in Nauru. Diabetes Care 19(7):710-714. https://doi.org/10.2337/diacare.19.7.710

7. Tseng CH (2006) Prevalence of lower-extremity amputation among patients with diabetes mellitus: is height a factor? CMAJ 174(3): 319-323. https://doi.org/10.1503/cmaj.050680

8. Zhou ZY, Liu YK, Chen HL, Yang HL, Liu F (2015) HbA1c and lower extremity amputation risk in patients with diabetes: a metaanalysis. Int J Low Extrem Wounds 14(2):168-177. https://doi.org/ $10.1177 / 1534734615593190$

9. The DCCT Research Group (1995) The relationship of glycemic exposure (HbA1c) to the risk of development and progression of retinopathy in the diabetes control and complications trial. Diabetes 44(8):968-983

10. UK Prospective Diabetes Study (UKPDS) Group (1998) Intensive blood-glucose control with sulphonylureas or insulin compared with conventional treatment and risk of complications in patients with type 2 diabetes (UKPDS 33). Lancet 352(9131):837-853

11. Hirsch IB (2005) Glycemic variability: it's not just about A1C anymore! Diabetes Technol Ther 7(5):780-783. https://doi.org/10. 1089/dia.2005.7.780

12. Hirsch IB, Brownlee M (2005) Should minimal blood glucose variability become the gold standard of glycemic control? J Diabetes Complicat 19(3):178-181. https://doi.org/10.1016/j.jdiacomp. 2004.10.001

13. Gorst C, Kwok CS, Aslam S et al (2015) Long-term glycemic variability and risk of adverse outcomes: a systematic review and meta-analysis. Diabetes Care 38(12):2354-2369. https://doi.org/10. 2337/dc15-1188

14. Nalysnyk L, Hernandez-Medina M, Krishnarajah G (2010) Glycaemic variability and complications in patients with diabetes mellitus: evidence from a systematic review of the literature. Diabetes Obes Metab 12(4):288-298. https://doi.org/10.1111/j. 1463-1326.2009.01160.x

15. Smith-Palmer J, Brandle M, Trevisan R, Orsini Federici M, Liabat S, Valentine W (2014) Assessment of the association between 
glycemic variability and diabetes-related complications in type 1 and type 2 diabetes. Diabetes Res Clin Pract 105(3):273-284. https://doi.org/10.1016/j.diabres.2014.06.007

16. Dhatariya KK, Ping L, Wah-Pun Sin E, Cheng JOS et al (2018) The impact of glycaemic variability on wound healing in the diabetic foot - a retrospective study of new ulcers presenting to a specialist multidisciplinary foot clinic. Diabetes Res Clin Pract 135:23-29. https://doi.org/10.1016/j.diabres.2017.10.022

17. Kilpatrick ES, Rigby AS, Atkin SL (2008) A1C variability and the risk of microvascular complications in type 1 diabetes: data from the Diabetes Control and Complications Trial. Diabetes Care 31(11):2198-2202. https://doi.org/10.2337/dc08-0864

18. Zhou JJ, Schwenke DC, Bahn G, Reaven P (2018) Glycemic variation and cardiovascular risk in the Veterans Affairs Diabetes Trial. Diabetes Care 41(10):2187-2194. https://doi.org/10.2337/dc180548

19. Levey AS, Stevens LA, Schmid CH et al (2009) A new equation to estimate glomerular filtration rate. Ann Intern Med 150(9):604 612. https://doi.org/10.7326/0003-4819-150-9-200905050-00006

20. Chen HF, Ho CA, Li CY (2006) Age and sex may significantly interact with diabetes on the risks of lower-extremity amputation and peripheral revascularization procedures: evidence from a cohort of a half-million diabetic patients. Diabetes Care 29(11):24092414. https://doi.org/10.2337/dc06-1343

21. Li W, Maloney RE, Aw TY (2015) High glucose, glucose fluctuation and carbonyl stress enhance brain microvascular endothelial barrier dysfunction: implications for diabetic cerebral microvasculature. Redox Biol 5:80-90. https://doi.org/10.1016/j.redox.2015. 03.005

22. Yuan T, Yang T, Chen $\mathrm{H}$ et al (2019) New insights into oxidative stress and inflammation during diabetes mellitus-accelerated atherosclerosis. Redox Biol 20:247-260. https://doi.org/10.1016/j. redox.2018.09.025

23. Chen J, Jing J, Yu S et al (2016) Advanced glycation endproducts induce apoptosis of endothelial progenitor cells by activating receptor RAGE and NADPH oxidase/JNK signaling axis. Am J Transl Res 8(5):2169-2178

24. Su DF (2006) Treatment of hypertension based on measurement of blood pressure variability: lessons from animal studies. Curr Opin Cardiol 21(5):486-491. https://doi.org/10.1097/01.hco. 0000240587.14463 .58

25. Hamza SM, Dyck JR (2014) Systemic and renal oxidative stress in the pathogenesis of hypertension: modulation of long-term control of arterial blood pressure by resveratrol. Front Physiol 5:292 https://doi.org/10.3389/fphys.2014.00292
26. Lancet (2018) Making more of multimorbidity: an emerging priority. Lancet 391(10131):1637. https://doi.org/10.1016/s01406736(18)30941-3

27. Jowsey T, McRae IS, Valderas JM et al (2013) Time's up. Descriptive epidemiology of multi-morbidity and time spent on health related activity by older Australians: a time use survey. PLoS One 8(4):e59379. https://doi.org/10.1371/journal.pone. 0059379

28. Lavery LA, Armstrong DG, Wunderlich RP, Mohler MJ, Wendel CS, Lipsky BA (2006) Risk factors for foot infections in individuals with diabetes. Diabetes Care 29(6):1288-1293. https://doi.org/10. 2337/dc05-2425

29. Pickwell K, Siersma V, Kars M et al (2015) Predictors of lowerextremity amputation in patients with an infected diabetic foot ulcer. Diabetes Care 38(5):852-857. https://doi.org/10.2337/dc14-1598

30. Lipsky BA, Weigelt JA, Sun X, Johannes RS, Derby KG, Tabak YP (2011) Developing and validating a risk score for lower-extremity amputation in patients hospitalized for a diabetic foot infection. Diabetes Care 34(8):1695-1700. https://doi.org/10.2337/dc110331

31. Monteiro-Soares M, Dinis-Ribeiro M (2016) A new diabetic foot risk assessment tool: DIAFORA. Diabetes Metab Res Rev 32(4): 429-435. https://doi.org/10.1002/dmrr.2785

32. Ferreira L, Carvalho A, Carvalho R (2018) Short-term predictors of amputation in patients with diabetic foot ulcers. Diabetes Metab Syndr 12(6):875-879. https://doi.org/10.1016/j.dsx.2018.05.007

33. Shatnawi NJ, Al-Zoubi NA, Hawamdeh HM, Khader YS, Garaibeh $\mathrm{K}$, Heis HA (2018) Predictors of major lower limb amputation in type 2 diabetic patients referred for hospital care with diabetic foot syndrome. Diabetes Metab Syndr Obes 11:313-319. https://doi. org $/ 10.2147 /$ dmso.S165967

34. Hippisley-Cox J, Coupland C (2015) Development and validation of risk prediction equations to estimate future risk of blindness and lower limb amputation in patients with diabetes: cohort study. BMJ 351:h5441. https://doi.org/10.1136/bmj.h5441

35. Boyko EJ, Seelig AD, Ahroni JH (2018) Limb- and person-level risk factors for lower-limb amputation in the prospective Seattle Diabetic Foot Study. Diabetes Care 41(4):891-898. https://doi. org $/ 10.2337 / \mathrm{dc} 17-2210$

Publisher's note Springer Nature remains neutral with regard to jurisdictional claims in published maps and institutional affiliations. 